Research Article

\title{
Study of effects of antiepileptic therapy on various biochemical and hematological parameters patients suffering of epilepsy
}

\author{
Uma A. Bhosale*, Neha R. Loharkar, Radha Yegnanarayan, Nilofar Quraishi
}

Department of Pharmacology, Smt. Kashibai Navale Medical College and General Hospital, Narhe (Ambegaon) - 411 041, Pune, India

Received: 8 November 2013

Revised: 25 November 2013

Accepted: 9 December 2013

\section{*Correspondence to:}

Dr. Uma A. Bhosale,

Email: umabhosale2000@gmail.com

\section{(C) 2014 Bhosale UA et al. This is an} open-access article distributed under the terms of the Creative Commons Attribution Non-Commercial License, which permits unrestricted noncommercial use, distribution, and reproduction in any medium, provided the original work is properly cited.

\begin{abstract}
Background: Low therapeutic index of established antiepileptic drugs (AEDs) coupled with better understanding of the pathophysiology of seizure has encouraged the development of several novel AEDs. The conventional antiepileptics like phenytoin, phenobarbitone, valproate and carbamazepine and newer antiepileptics like levetiracetam, lamotrigine and topiramate etc. are used for epilepsy. AEDs induce potentially toxic effects over a period of time which remains undetermined over very long time. Earlier studies in this regard, states uneven results about biochemical (i.e. blood sugar level, lipid profile) and hematological ( $\mathrm{Hb} \%$, blood cell count etc.) toxicity of AEDs. Aims: To unveil the toxic effects of AEDs when given singly or as combinations.

Methods: Adult epileptics of either sex taking antiepileptic monotherapy or combination therapy for $\geq$ six months were enrolled. Biochemical and hematological parameters studied were compared with their age and sex matched controls, baseline and amongst groups. Statistical Analysis Used: Student's 't'-test \& One way ANOVA followed by posthoc Tukey HSD test for pair wise comparison; $\mathrm{p}<0.05$ was considered significant.

Results: Conventional antiepileptic combination therapy was found more toxic; $\mathrm{p}<0.01$ for lipid profile. Combination groups showed significant reduction in $\mathrm{Hb} \%(\mathrm{p}<0.05)$ with no significant difference among them ( $>0.05)$. Monotherapy and conventional combination therapy caused significant reduction in platelet count $(\mathrm{p}<0.01)$, but conventional combination therapy was found more toxic in this regard $(\mathrm{p}<0.05)$.

Conclusions: Monotherapy found less toxic with no significant effects on lipid profile, $\mathrm{Hb} \%, \mathrm{RBC}$ count and $\mathrm{O}_{2}$ carrying capacity and less impact on platelets while combination therapy did not show any advantage over monotherapy and its use must be reserved only for refractory cases.
\end{abstract}

Keywords: Antiepileptics, Pharmacovigilance, Monotherapy,

\section{INTRODUCTION}

A seizure or convulsion is a paroxysmal time-limited change in motor activity and/or behavior that results from abnormal electrical activity in the brain. It is one of the most common neurological disorders which know no geographical, racial or social boundaries. The incidence is approximately $0.3-0.5 \%$ in different world populations with a prevalence rate of five to ten per thousand people. ${ }^{1}$ Since 1850 , antiepileptic drugs (AEDs) are in use. Majority of patients can be treated with conventional drugs like phenytoin (PHT), phenobarbitone
(PB), valproate (VPA) and carbamazepine (CBZ) \& many new drugs like levetiracetam (LEV), lamotrigine (LTG) and topiramate (TPR), tiagabine (TBG) etc. are currently used as add-on or alternative therapy. ${ }^{1}$

Patients with epilepsy may manifest metabolic adverse effects through the course of their management with AEDs. Such effects may be subtle, insidious, take many years to become clinically apparent, and may have a negative impact on general health for many decades. Unfortunately, many neurologists are unaware of such AED-related side-effects. ${ }^{2}$ According to previous studies, 
conventional drug therapy \& also their combination therapy are responsible for increase in total serum cholesterol levels ${ }^{3,4}$ \& blood sugar level (BSL). ${ }^{5,6}$ Also antiepileptic drugs are hematotoxic i.e. there is decrease in haemoglobin concentration, RBC \& WBC counts after long term antiepileptic therapy. ${ }^{7}$ In contrast to these findings some studies mention that AEDs do not have any effect on the biochemical and hematological parameters of epileptic patients. ${ }^{8}$

Screening for adverse reactions to AEDs is not systematically included in everyday clinical practice; and it is very likely that it remains underestimated. Hence present study was undertaken to unveil the potential toxic effects of antiepileptics with reference to biochemical and hematological parameters. It's an attempt to comparatively explore future avenues for clinical research in the pharmacological management of the epilepsies involving rational use of AEDs, both singly and in combination.

\section{METHODS}

The study protocol has been approved by Institutional Ethics Committee (Approval letter no: Ref. SKNMC No/Ethics/App/2011/90; date: 15/12/2011).

\section{Study Design}

Adult epileptics of either sex taking antiepileptic monotherapy (PHT/CBZ/PB/VPA) or combination therapy (conventional AEDs and conventional with newer AEDs like LEV, LTG \& TPR etc.) for more than six months were enrolled in the study. The patients with diabetes, HTN, IHD, stroke, malignancy, arthritis, renal/hepatic disease and any disease other than epilepsy for which medicine was taken over long time excluded from study. The old (at least 6 months) records of biochemical and hematological parameters of these epileptics were noted as baseline records and compared with the parameters recorded at the time of enrollment. For the patients with no such old records, investigations were carried out on the day of enrolment and these results considered as their baseline records; six months later investigations were repeated and results compared with baseline. The biochemical and hematological parameters studied were also compared with their age and sex matched controls. The study was further extended to comparatively explore the impact of monotherapy and combination therapy on biochemical and hematological parameters in epileptic patients.

\section{Sample collection}

$5 \mathrm{ml}$ of blood sample was collected; out of that $4 \mathrm{ml}$ was taken in sterile plain bulbs and $1 \mathrm{ml}$ in EDTA bulb. The samples in sterile plain bulbs were sent to central clinical laboratory on the same day for estimation of BSL random (R) and lipid profile and in EDTA bulb for complete blood count (CBC).

\section{Methods}

- Height and weight was measured to calculate BMI using online calculator.

- Blood samples were collected from epileptic patients attending medicine OPD and admitted in medicine wards; BSL(R), lipid profile and CBC were checked by routine laboratory methods. $\mathrm{O}_{2}$ carrying capacity was calculated by following formula,

$$
\mathrm{O}_{2} \text { carrying capacity }=\mathrm{Hb} \%(\mathrm{~g} / \mathrm{dl}) \times 1.34^{9}
$$

\section{Statistical analysis}

Data obtained was analyzed using Vassar-stats software. Statistical tests used were student's 't'-test and ANOVA followed by posthoc Tukey HSD test for pair wise comparison.

\section{RESULTS}

Baseline demographic characteristics at the time of screening were found uniform in all groups (Table 1).

Table 1: Baseline demographic characteristics at screening.

\begin{tabular}{|clll|} 
Sr. No. & Character & Control & $\begin{array}{l}\text { Antiepileptic } \\
\text { group }\end{array}$ \\
\hline 1. & Sex & & \\
\hline & Male & $11(36.7)$ & $11(36.7)$ \\
& Female & $19(63.3)$ & $19(63.3)$ \\
\hline 2. & Age (years) & $43.1 \pm 1.8$ & $43.1 \pm 1.8$ \\
\hline 3. & Height $(\mathrm{cm})$ & $150 \pm 3.7$ & $158 \pm 7$ \\
\hline 4. & Weight $(\mathrm{Kg})$ & $52.3 \pm 2.4$ & $50.6 \pm 4$ \\
\hline 5. & BMI $\left(\mathrm{kg} / \mathrm{cm}^{2}\right)$ & $23.3 \pm 3.3$ & $22.4 \pm 1$ \\
\hline
\end{tabular}

CBZ and PHT were amongst most prescribed AEDs as monotherapy and as combination therapy as well with VPA; while LEV and LTG were found frequently prescribed amongst newer AEDs (Table 2, Figure 1). This study clearly revealed that all of the AEDs are potential toxic drugs; as all have significantly impaired lipid and hematological profile of the epileptics when compared to their controls and baseline records (Table 3 $\&$ 4). However the conventional antiepileptic combination therapy was found more toxic in this regard; $\mathrm{p}<0.01$ for total cholesterol, triglycerides and LDL (see figure 2). HDL levels were significantly reduced in both combination therapy groups; $\mathrm{p}<0.01$, but this was significantly more in conventional combination group; $\mathrm{p}<0.05$. BSL nevertheless showed no significant increase in any of the group (Table $3 \&$ Figure 2). Both combination therapy groups showed significant reduction in $\mathrm{Hb} \%$; $<<0.05$ but no significant difference was found between these groups; $\mathrm{p}>0.05$. Monotherapy and conventional antiepileptic combination therapy both caused significant reduction in platelet count; $\mathrm{p}<0.01$ but conventional antiepileptic combination therapy was found more toxic in this regard; $\mathrm{p}<0.05$. 
Table 2: Categorization of patients on the basis of antiepileptic therapy given.

\begin{tabular}{|c|c|c|c|c|}
\hline Sr. No. & Therapy & Drugs & No of patients \% & Duration (yrs) \\
\hline \multirow{4}{*}{1} & \multirow{4}{*}{ Monotherapy } & 1. Carbamazepine & 50 & $4-6$ \\
\hline & & 2. Phenytoin & 30 & $2-5$ \\
\hline & & 3. Phenobarbitone & 10 & 06 \\
\hline & & 4. Valproate & 10 & 02 \\
\hline \multirow{4}{*}{2} & Conventional & 1. Phenytoin+ Phenobarbitone & 10 & 15 \\
\hline & antiepileptic & 2. Carbamazepine+ Phenobarbitone & 20 & $5-8$ \\
\hline & combination & 3. Valproate + Phenytoin & 30 & $5-8$ \\
\hline & therapy & 4. Valproate + Carbamazepine & 40 & $4-10$ \\
\hline \multirow{4}{*}{3} & \multirow{4}{*}{$\begin{array}{l}\text { Newer }+ \\
\text { conventional } \\
\text { antiepileptic } \\
\text { combination } \\
\text { therapy }\end{array}$} & 1. Carbamazepine + clobazam + topiramate & 20 & 02 \\
\hline & & 2. Carbamazepine + clobazam + levetiracetam & 30 & $2-4$ \\
\hline & & 3. Carbamazepine + phenobarbitone + levetiracetam & 10 & $1-2$ \\
\hline & & 4. Valproate + lamotrigine & 40 & $3-5$ \\
\hline
\end{tabular}

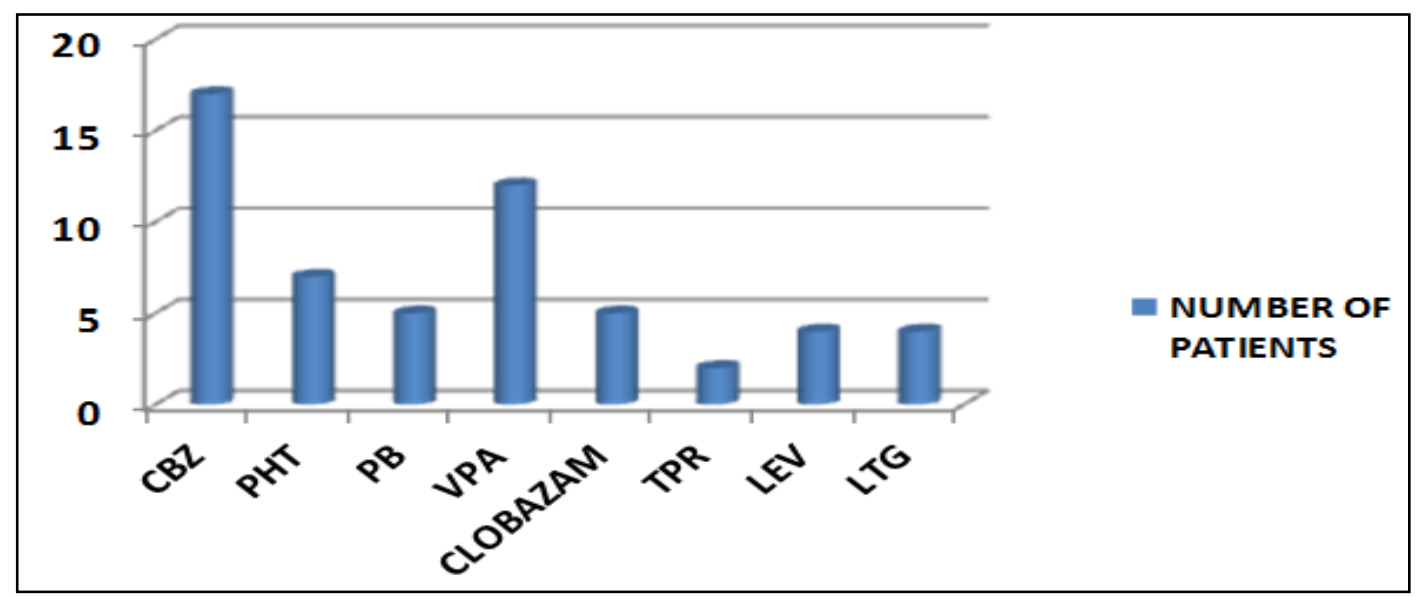

Figure 1: Types and frequencies of $\operatorname{AEDs}(n=30)$.

Table 3: Categorization of patients on the basis of antiepileptic therapy given.

\begin{tabular}{|cllll|}
\hline Sr. No. & Observations (mg/dl) & Control & $\begin{array}{l}\text { Antiepileptic group } \\
\text { (baseline) }\end{array}$ & $\begin{array}{l}\text { Antiepileptic group } \\
\text { (after } \geq 6 \text { months) }\end{array}$ \\
\hline 1. & BSL(R) & $100.0 \pm 1.2$ & $101.2 \pm 1.4$ & $104.4 \pm 1.3$ \\
\hline 2. & Total Cholesterol & $118.4 \pm 10.2$ & $142.5 \pm 4.3$ & $\dagger 148.4 \pm 7^{*}$ \\
\hline 3. & Sr. Triglycerides & $72.4 \pm 5.4$ & $76.5 \pm 3.7$ & $\dagger \dagger \dagger 140.3 \pm 2.4^{*}$ \\
\hline 4. & Sr.HDL & $49 \pm 3$ & $52 \pm 2.6$ & $\dagger 37.9 \pm 4.4^{* *}$ \\
\hline 5. & Sr. LDL & $84.9 \pm 6.4$ & $90.9 \pm 2.9$ & $\dagger 109.81 \pm 4.4^{*}$ \\
\hline 6. & Sr. VLDL & $14.5 \pm 0.5$ & $18.3 \pm 1.8$ & $\dagger \dagger \dagger 28.1 \pm 1.1^{* *}$ \\
\hline
\end{tabular}

$\mathrm{n}=30$, Values are mean $\pm \mathrm{SD} ; \dagger \mathrm{p}<0.05, \dagger \dagger \mathrm{p}<0.01$ and $\dagger \dagger \uparrow \mathrm{p}<0.001$ compared to control

${ }^{*} \mathrm{p}<0.05, * * \mathrm{p}<0.01$ and $* * * \mathrm{p}<0.001$ compared to baseline records

$\mathrm{O}_{2}$ carrying capacity was found to be reduced in combination therapy groups; $\mathrm{p}<0.05$ for both. Monotherapy found less toxic with no significant effects on lipid profile, $\mathrm{Hb} \%, \mathrm{RBC}$ count and $\mathrm{O}_{2}$ carrying capacity; $\mathrm{p}>0.05$ and less impact on platelet count compared to conventional combination therapy; while the WBC count was significantly reduced in monotherapy group; $\mathrm{p}<0.01$ (Figure 3), this toxicity was found to be prominent in PHT and PB treated patients over a period of time. 
Table 2: Effects of antiepileptics on hematological parameters.

\begin{tabular}{|lllll|}
\hline Sr. No. & Observations & Control group & $\begin{array}{l}\text { Antiepileptic group } \\
\text { (baseline) }\end{array}$ & $\begin{array}{l}\text { Antiepileptic group } \\
\text { (after } \geq 6 \text { months) }\end{array}$ \\
\hline 1. & $\mathrm{Hb} \%(\mathrm{~g} / \mathrm{dl})$ & $13.4 \pm 0.6$ & $13.8 \pm 0.8$ & $\dagger 12.5 \pm 0.4^{* * *}$ \\
\hline 2. & RBC count $\left(\mathrm{x} 10^{6} / \mathrm{mm}^{3}\right)$ & $8.8 \pm 0.5$ & $5.2 \pm 0.6$ & $4.6 \pm 0.4$ \\
\hline 3. & WBC count $\left(10^{3} / \mathrm{mm}^{3}\right)$ & $7.8 \pm 0.3$ & $7.9 \pm 0.8$ & $\dagger \dagger \dagger 6 \pm 0.1^{* * *}$ \\
\hline 4. & Platelets $\left(\mathrm{x} 10^{5} / \mathrm{mm}^{3}\right)$ & $2.2 \pm .3$ & $2.8 \pm .2$ & $1.95 \pm .3^{*}$ \\
\hline 5. & $\mathrm{O}_{2}$ carrying capacity $(\mathrm{ml} / \mathrm{dl})$ & $18 \pm 0.8$ & $18.5 \pm 0.8$ & $\dagger 16.7 \pm 0.5^{*}$ \\
\hline
\end{tabular}

$\mathrm{n}=30$, Values are mean $\pm \mathrm{SD} ; \dagger \mathrm{p}<0.05, \uparrow \dagger \mathrm{p}<0.01$ and $\dagger \dagger \uparrow \mathrm{p}<0.001$ compared to control

${ }^{*} \mathrm{p}<0.05, * * \mathrm{p}<0.01$ and $* * * \mathrm{p}<0.001$ compared to baseline records (Thrombocytopenia was seen in patients treated with VPA, PHE and PB singly or as combination, while leucopenia was prominent in PHT and CBZ treated patients)

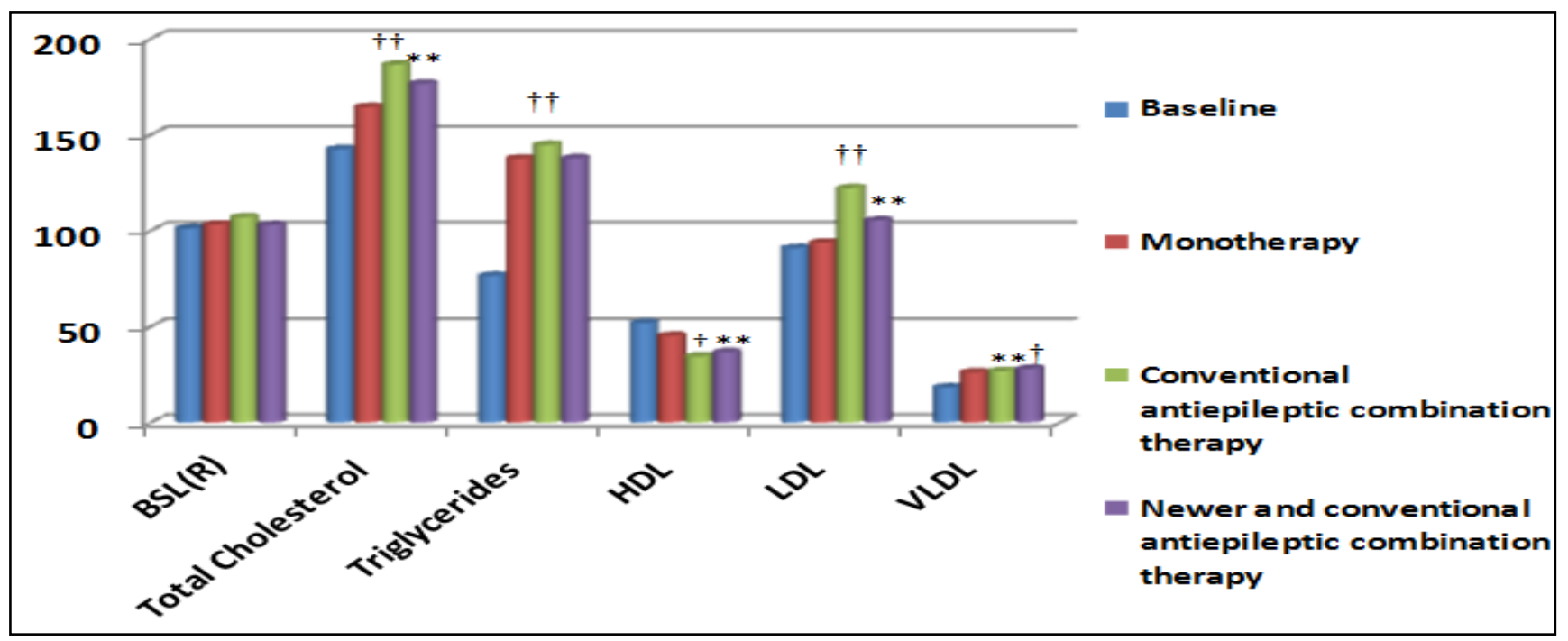

Figure 2: Comparative biochemical toxicity of antiepileptic monotherapy \& combination therapy (for $\geq 6$ months).

${ }^{*} \mathrm{p}<0.05, * * \mathrm{p}<0.01, \dagger \mathrm{p}<0.05, \dagger \dagger \mathrm{p}<0.01$; with one way ANOVA followed by posthoc Tukey HSD test for pair wise comparison. (*compared to monotherapy, †comparison between combination therapy)

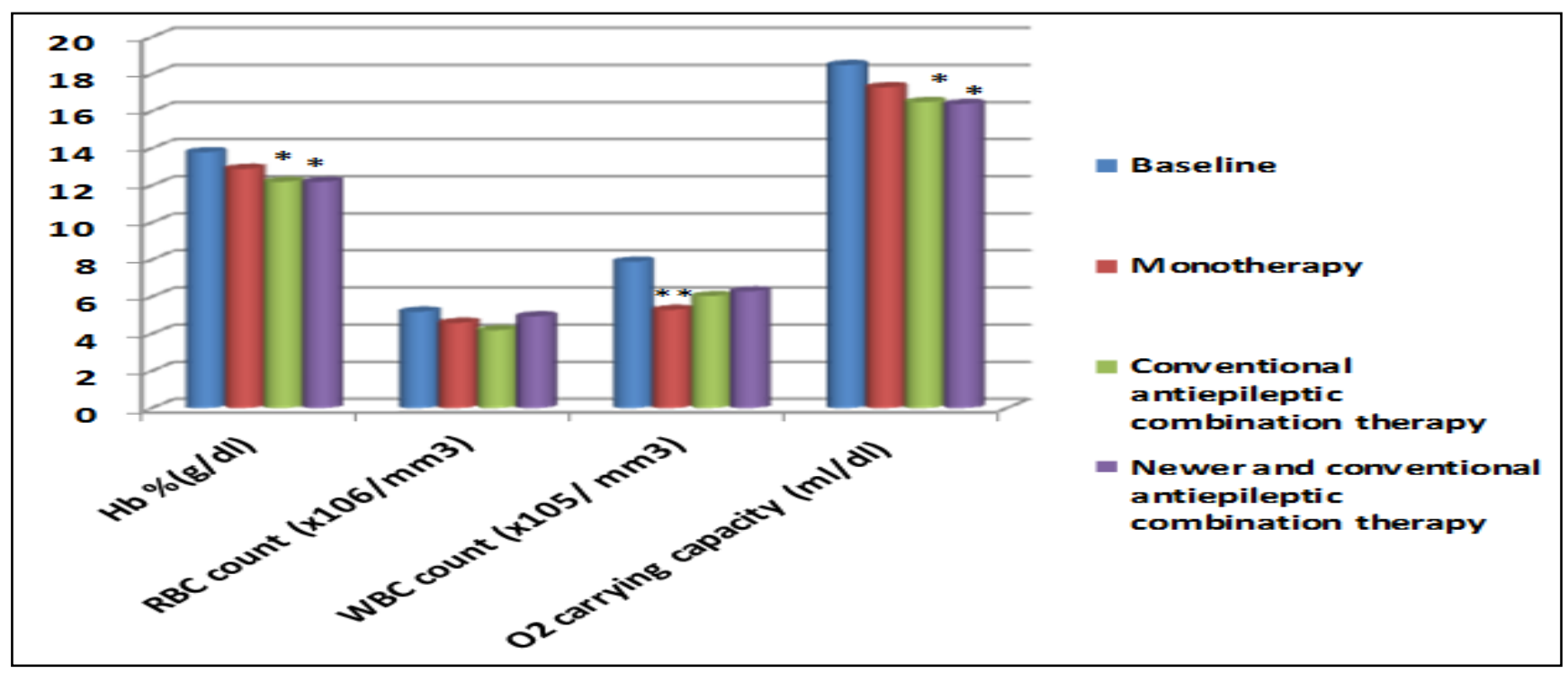

Figure 3A: Comparative hematological toxicity of antiepileptic monotherapy and combination therapy (for $\geq 6$ months). 


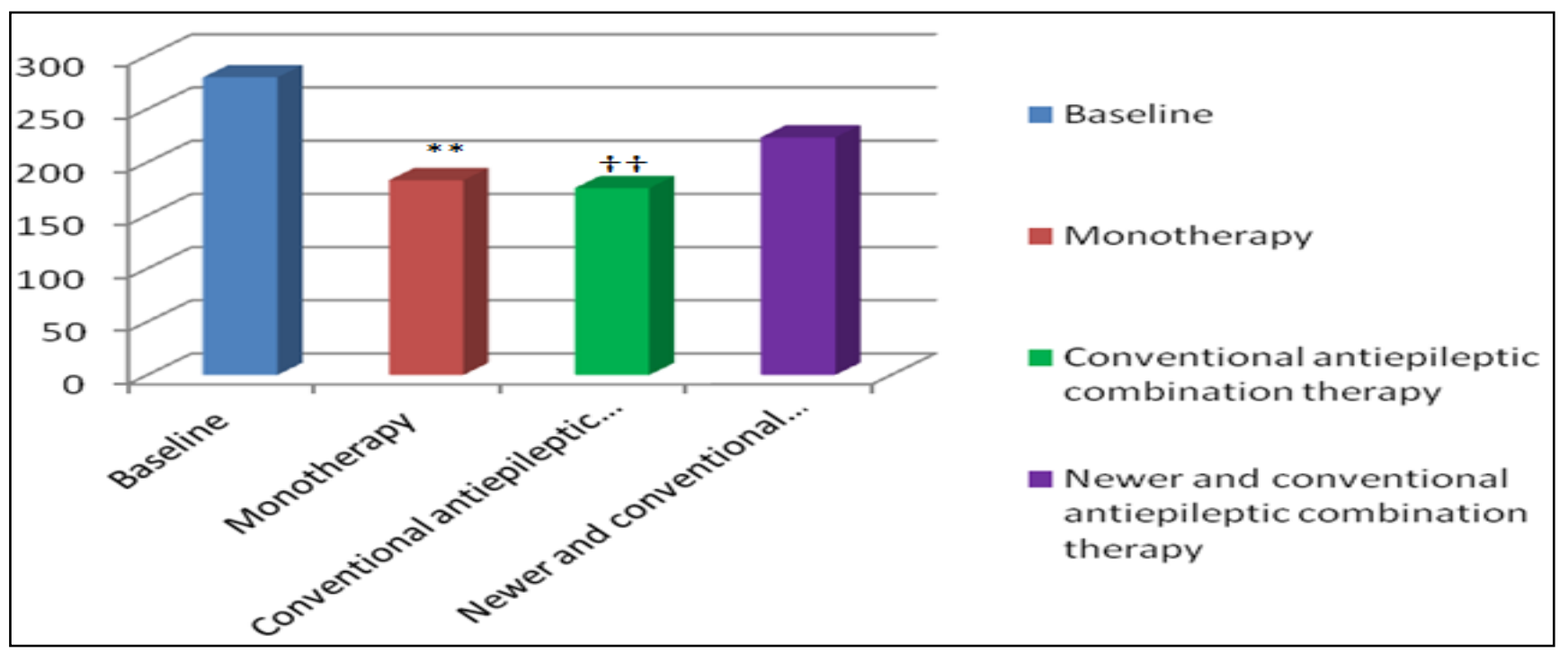

Figure 3B: Platelet count $\left(\mathrm{x} 10^{3} / \mathrm{mm}^{3}\right)$.

${ }^{*} \mathrm{p}<0.05, * * \mathrm{p}<0.01, \dagger \mathrm{p}<0.05, \dagger \dagger \mathrm{p}<0.01$; with one way ANOVA followed by posthoc Tukey HSD test for pair wise comparison. (*compared to monotherapy, †comparison between combination therapy)

\section{DISCUSSION}

AEDs are associated with panoply of metabolic and haemopoetic abnormalities; results of our study shore up this statement. Although BSL is spared; lipid profile of epileptic patients was significantly affected by AEDs. Majority of the epileptics $(83.33 \%)$ were treated with PHT, PB and CBZ either as monotherapy (90\%) or as combination therapy (100\% conventional and $60 \%$ with newer with conventional AEDs). PHT, PB and CBZ are potent enzyme inducers and induce cytochrome $\mathrm{P} 450$ system. ${ }^{10,11}$ The CYP450 enzyme system is involved in the synthesis and metabolism of cholesterol ${ }^{[12]}$. In particular, CYP51A1 plays a key role in cholesterol synthesis. ${ }^{13}$ Enzyme-inducing AEDs would therefore be expected to increase cholesterol production. And so are the results i.e. all groups showed impairment in lipid profile to variable extent compared to controls and their baseline records. This impairment was significant with conventional antiepileptic combination with two enzyme inducer AEDs compared to monotherapy and newer antiepileptic combination therapy group. PHT is known to induce hyperglycemia by inhibiting insulin release and by insulin insensitivity that results due to post-binding defect induction in insulin action. ${ }^{6,14}$ In our study PHT was given to relatively less number of epileptics $(23.3 \%)$, this could be the reason for insignificant effects on BSL. Valproate is reported to cause glucose intolerance exclusively in overweight patients, however in our study groups mean weight was found to be $50.6 \mathrm{~kg}$ with BMI $22.4 \mathrm{~kg} / \mathrm{cm}^{2}$ this could be another reason for insignificant effects on BSL though significant number of patient $(40 \%)$ were on valproate therapy. ${ }^{15}$

Folate is important for cells and tissues that rapidly divide e.g. bone marrow. ${ }^{16}$ Anti-folic acid activity of antiepileptics like CBZ, oxaCBZ, PHT, PB, LTG and
VPA etc. is responsible for bone marrow depression that results in blood dyscrasias like thrombocytopenia, leucopenia and aplastic anemia. ${ }^{17}$ Platelet count was significantly reduced in epileptic treated with CBZ, PHT, PB and VPA $(66.6 \%)$ as monotherapy or combination therapy compared to newer AEDs combination therapy (33.3\%). This toxicity was prominent in VPA, PHE and PB treated epileptics singly or as combination at the same time leucopenia was significant in PHT and CBZ treated monotherapy group patients $(26.6 \%)$. Folic acid is itself not biologically active, but its biological importance is due to tetrahydrofolate and other derivatives after its conversion to dihydrofolic acid in the liver by dihydrofolate reductase. This reductase is said to be blocked by AEDs. ${ }^{18}$ Anti- folate activity can also lead to decreased $\mathrm{Hb} \%$ and homocysteine accumulation ${ }^{19}$ which further affect lipid metabolism. ${ }^{20}$ Ultimately resulting into biochemical and hematological toxicity, these results are in agreement with earlier studies stating biochemical and hematological toxicity of $\mathrm{AEDs}^{21-25}$ and in disagreement with the studies stating AEDs have minimal or no effects on hematological and biochemical parameters. ${ }^{8,26}$ In this study it was found that monotherapy has overall less toxic effects on lipid profile, $\mathrm{Hb} \%, \mathrm{RBC}$ count and $\mathrm{O}_{2}$ carrying capacity compared to combination therapy; although it found less promising than newer AEDs combination therapy pertaining to platelet count and WBC count.

Epileptic patients in $70 \%$ are seizure free with one drug based on cautious drug administration and dosage modification. Judgment to treatment of epilepsy is normally based on monotherapy. AEDs combination therapy may contribute to cause side effects in patients. ${ }^{27}$,

${ }^{28}$ Hence it is advisable to start the therapy with single antiepileptic and rather combining an additional conventional AED, combine a newer antiepileptic as an add-on therapy for optimal seizure control with minimal adverse effects unlike conventional AEDs combinations. 


\section{CONCLUSION}

From the results of this study it can be concluded that, all the antiepileptics are potentially toxic drugs. They produce varied adverse effects, but these are the drugs that improve quality of life of epileptics and their judicious use is necessary for effective and safe treatment of epilepsy. It is reported that combination therapy does not have advantage over monotherapy, hence its must be emphasized that monotherapy is a gold standard in antiepileptic therapy and combination therapy should be advocated with caution only if patient is refractory to monotherapy.

\section{Funding: No funding sources}

Conflict of interest: None declared

Ethical approval: Approval was taken from the institutional ethics committee

\section{REFERENCES}

1. Shobhana Mathur, Sumana Sen, L Ramesh, Satish Kumar M. Utilization pattern of anntiepileptic drugs and their adverse effects, in a teaching hospital. Asian Journal of Pharmaceutical and Clinical Research. 2010;3(1):55-9.

2. Annegers, J.F.; Hauser, W.A. \& Shirts, S.B. Heart disease mortality and morbidity in patients with epilepsy. Epilepsia. 1984;25:699-704.

3. Rai Yogesh, Kumar, Misra Harsh, Misra Asha. Effect of anticonvulsant drugs on lipid profile in epileptic patients. Indian Journal of Public Health Research \& Development. 2010;1(1):46-50.

4. Manisha Naithani, Sunny Chopra, B L Somani, R K Singh, Shri Guru Ram Rai, Patel Nagar. Studies on adverse metabolic effects of antiepileptic and their correlation with blood components. Current Neurobiology. 2010;1(2):117-20.

5. Demir E, Aysun S. Weight gain associated with valproate in childhood. Pediatr Neurol. 2000;22:3614.

6. Carter BL, Small RE, Mandel MD, Starkman MT. Phenytoin-induced hyperglycemia. Am J Hosp Pharm. 1981;38(10):1508-12.

7. Jawad S, Mercer A, Jamil N, Richens A. Haematological values of epileptic patients entering drug trials. International Journal of Clinical Pharmacology Research. 1988;8(5):363-6.

8. Pee DH, Park YK, Eun BL, Park SH, Kim SK. The Hematologic Effect of Antiepileptic Drugs. J Korean Pediatr Soc. 1997 Feb; 40(2):217-224.

9. Guyton AC, Hall JE. Text Book of Medical Physiology. 11th ed. Elsevier; New Delhi. 2006: 419-468.

10. Mintzer S, Skidmore CT, Abidin CJ, Morales MC, Chervoneva I, Capuzzi DM, Sperling MR. Effects of antiepileptic drugs on lipids, homocysteine, and C-reactive protein. Ann Neurol. 2009;65(4):448-56.
11. Mintzer S. Metabolic consequences of antiepileptic drugs. Curr Opin Neurol. 2010;23(2):164-9.

12. Nebert, D.W. Russel, D.W. Clinical importance of the cytochromes P450. Lancet. 2002;360:1155-62.

13. Gibbons, G.F. The role of cytochrome P450 in the regulation of cholesterol biosynthesis. Lipids. 2002;37:1163-70.

14. Al-Rubeaan K, Ryan EA. Phenytoin-induced insulin insensitivity. Diabet Med. 1991;8(10):968-70.

15. Verotti, A.; Manco, R.; Agostinelli, S. et al. The metabolic syndrome in overweight epileptic patients treated with valproic acid. Epilepsia. 2010;51(2): 268-73.

16. Kamen B. Folate and antifolate pharmacology. Semin. Oncol. 1997;24(5):S18-30-9.

17. Koby Brosh, Ilan Matok, Eyal Sheiner, Gideon Koren, Arnon Wiznitzer, Rafael Gorodischer, Amalia Levy. Teratogenic Determinants of FirstTrimester Exposure to Antiepileptic Medications. J Popul Ther Clin Pharmacol. 2011;18(1):e89-98.

18. Bailey SW, Ayling JE. The extremely slow and variable activity of dihydrofolate reductase in human liver and its implications for high folic acid intake. Proceedings of the National Academy of Sciences of the United States of America. 2009;106 (36):154249.

19. Weinstein SJ, Hartman TJ, Stolzenberg-Solomon $\mathrm{R}$, et al. Null association between prostate cancer and serum folate, vitamin $\mathrm{B}(6)$, vitamin $\mathrm{B}(12)$, and homocysteine. Cancer Epidemiol. Biomarkers Prev. 2003;12 (11 Pt 1):1271-2.

20. Selhub, J. Homocysteine metabolism. Annual Review of Nutrition. 1999;19:217-46.

21. Bachmann $\mathrm{T}$, Bertheussen $\mathrm{KH}$, Svalheim S, Rauchenzauner M, Luef G, Gjerstad L, Taubøll E. Haematological side effects of antiepileptic drug treatment in patients with epilepsy. Acta Neurol Scand Suppl. 2011;91:23-7.

22. Handoko KB, Souverein PC, van Staa TP, Meyboom RH, Leufkens HG, Egberts TC, vanden Bemt PM: Risk of aplastic anemia in patients using antiepileptic drugs. Epilepsia. 2006;47:1232-6.

23. Farkas V, Szabó M, Rényi I, Kohlhéb O, Benninger $\mathrm{C}$ : Temporary pure red-cell aplasia during valproate monotherapy: clinical observations and spectral electroencephalographic aspects. J Child Neurol. 2000;15:485-7.

24. Seung Hee Jang, Eun Kyoung Choi, So Hee Eun, Sun Jun Kim Changes of Body Weight and Lipid Profiles According to Apolipoprotein E Polymorphism in Children with Antiepileptics. J Korean Pediatr Soc. 2002;45:88-94.

25. Raman Sankar. Initial treatment of epilepsy with antiepileptic drugs. Neurology 2004;63(4):S30-9.

26. Hadiza Aliyu, Joseph O. Ayo Suleiman F. Ambali, Abdulkadir U. Zezi. Effects of administration of carbamazepine and/or phenytoin on haematological parameters in wistar rats. African Journal of Pharmacy and Pharmacology. 2013;7(23):1585-91. 
27. Kramer MA, Cash SS. Epilepsy as a disorder of cortical network organization. Neuroscientist. 2012;18:360-72.
28. Johannessen SI, Landmark CJ. Antiepileptic drug interactions-principles and clinical implications. Curr Neuropharmacol. 2010;8:254-67.

doi:10.5455/2319-2003.ijbcp20140207

Cite this article as: Bhosale UA, Loharkar NR,

Yegnanarayan R, Quraishi N. Study of effects of antiepileptic therapy on various biochemical \& hematological parameters patients suffering of epilepsy. Int J Basic Clin Pharmacol 2014;3:79-85. 